\title{
Status Update on Translation of Integrated Primary Dental-Medical Care Delivery for Management of Diabetic Patients
}

\author{
Ingrid Glurich, PhD; Gregory Nycz; and Amit Acharya, BDS, PhD
}

\begin{abstract}
Escalating prevalence of both diabetes and periodontal disease, two diseases associated with bi-directional exacerbation, has been reported. Periodontal disease represents a modifiable risk factor that may reduce diabetes onset or progression, and integrated models of cross-disciplinary care are needed to establish and manage glycemic control in affected patients. An ad-hoc environmental scan of current literature and media sought to characterize factors impacting status of integrated care models based on review of the existing evidence base in literature and media surrounding: (I) current cross-disciplinary practice patterns, (2) epidemiological updates, (3) status on risk assessment and screening for dysglycemia in the dental setting, (4) status on implementation of quality metrics for oral health, (5) care model pilots, and (6) public health perspectives. The survey revealed: escalating prevalence of diabetes and periodontitis globally; greater emphasis on oral health assessment for diabetic patients in recent medical clinical practice guidelines; high knowledgeability surrounding oralsystemic impacts on diabetes and growing receptivity to medical-dental integration among medical and dental providers; increasing numbers of programs/studies reporting on positive impact of emerging integrated dental-medical care models on diabetic patient healthcare access and health outcomes; a growing evidence base for clinically significant rates of undiagnosed dysglycemia among dental patients reported by point-of- care pilot studies; no current recommendation for population-based screening for dysglycemia in dental settings pending a stronger evidence base; improved definition of true periodontitis prevalence in (pre)/diabetics; emerging recognition of the need for oral health quality indicators and tracking; evidence of persistence in dental access disparity; updated status on barriers to integration. The potential benefit of creating clinically-applicable integrated care models to support holistic management of an escalating diabetic population by targeting modifiable risk factors including periodontitis is being recognized by the health industry. Cross-disciplinary efforts supported by high quality research are needed to mitigate previously- and newly-defined barriers of care integration and expedite development and implementation of integrated care models in various practice settings. Implementation of quality monitoring in the dental setting will support definition of the impact and efficacy of interventional clinical care models on patient outcomes.
\end{abstract}

Keywords: Diabetes; Delivery of healthcare-integrated; Mass screening; Periodontitis; Risk assessment

\section{Overview}

Despite designation of periodontal disease (PD) as a complication of type 2 diabetes mellitus (T2DM) and recognition of bidirectional exacerbation of the two diseases by underlying inflammatory processes, ${ }^{1}$ siloed oral-medical healthcare and management of patients with T2DM persists. Evidence presented in this environmental scan increasingly supports recognition by all stakeholders that there is a growing need for implementing integrated dental-medical care approaches to healthcare delivery in the context of diabetic care. Epidemiological evidence reveals achievement of epidemic status globally for both conditions ${ }^{2,3}$ in the framework of current models of care, while a growing evidence base underlines both the need and plausibility of establishing new integrated healthcare delivery models for chronic disease management of these complex diseases, as

Received: October 27, 2016

Revised: March 2, 2017

Accepted: March 24, 2017

doi: $10.3121 / \mathrm{cmr} .2017 .1348$ 
Table 1. Current definitions of type diabetes mellitus and pre-diabetes.

\begin{tabular}{lll}
\hline Glycemic Parameter & T2DM & Pre-Diabetes \\
\hline Hemoglobin A1C (HbA1C) & $\geq 6.5 \%$ & $5.7-6.4 \%$ \\
Fasting plasma glucose (FPG) & $\geq 126 \mathrm{mg} / \mathrm{dl}(7.0 \mathrm{mmol} / \mathrm{L})$ & $100-125 \mathrm{mg} / \mathrm{dl}(5.6-6.9 \mathrm{mmol} / \mathrm{L})$ \\
Oral glucose tolerance test (OGTT) & $\geq 200 \mathrm{mg} / \mathrm{dl}(11.1 \mathrm{mmol} / \mathrm{L})$ & $140-199 \mathrm{mg} / \mathrm{dl}(7.8-11.0 \mathrm{mmol} / \mathrm{L})$ \\
\hline
\end{tabular}

Adapted from: American Diabetes Association. Standards of medical care in diabetes-2015 abridged for primary care providers Clin

Diabetes 2015;33:97-1112

summarized in this scan. This report sought to update the current status and progress in advancing establishment of models for integrated oral-dental healthcare delivery for patients with, or at risk for, diabetes.

\section{Approach}

An ad hoc environment scan was undertaken to descriptively characterize current status/outlooks for integration of oral health into primary care delivery, with focus on diabetic care. Ad hoc environmental scans are cross sectional surveys undertaken at unspecified frequency, for the purpose of reviewing the current relevant evidence base across a range of sources in an attempt to ascertain the current state of the art surrounding the specific topic under focus. Such scans are conducted to collect information that may inform future planning of various vested stakeholders.

Figure 1 summarizes resources and relevant topics that were explored through key word searches utilizing MESH terminology to identify relevant publications and online resources with respect to characterizing current state of the art in achieving integrated oral-medical care delivery to patients with dysglycemia or diabetes.

\section{Discussion}

Current Interdisciplinary Practice Patterns: Does Oral Health Factor into Current Clinical Practice Guidelines (CPGs) and Position Statements Surrounding T2DM Management?

Updated standards of medical care were defined by American Diabetic Association (ADA) in 2015, informed by critical evaluation of the current evidence-base, including updates to current diagnostic criteria for T2DM and prediabetes (summarized in Table 1). ${ }^{4}$ New recommendations included testing at any age for individuals meeting overweight/obesity criteria with one or more risk factor and all patients by age 45 years. Through 2015, guidance relative to oral health and diabetes largely consisted of recommendation by a physician for an annual oral examination. Notably, the 2016 guidelines published by the ADA more prominently featured attention to oral health in diabetic patients. As part of establishment of the medical history, comprehensive diabetes medical evaluation should include: "presence of common comorbidities including dental disease; recommendations for preventative care services including dental referrals' (page 23) ${ }^{5}$ and 'referrals to dentists for comprehensive dental and periodontal examination as a component of initial care management' (tables 3.1 and 3.2 on page S24). ${ }^{5}$ On page S31, ${ }^{5}$ under the subheading of
'Periodontal Disease' the guidelines note the potential for 'increased severity of PD' in diabetic patients and negative impacts on diabetes outcomes but noted that positive impact on diabetes outcomes in response to PD treatment 'remains controversial', citing outcomes of a 2013 systematic review of the current evidence base. ${ }^{6}$ These recommendations underline recognition of a need for better cross disciplinary care coordination for diabetic patients. Current guidelines do not presently include recommendations surrounding oral health management for gestational diabetes or oral health considerations in hospitalized patients with diabetes. The National Diabetes Education Initiative's ${ }^{7}$ treatment guideline repository surrounding diabetes has included links to these latest ADA standards.

Recommendations surrounding integrated care teams for management of diabetic patients featured in the Diabetes Mellitus Comprehensive Care Plan, ${ }^{8}$ jointly published by American Association Clinical Endocrinologists and American College of Endocrinology (2015), promotes inclusion of diabetes educators/dieticians on care teams based on evidence documenting efficacy of nutritional therapy in glycemic control maintenance and reduction of comorbid risk in randomized clinical trials. However, guidelines for nutritional intervention address neither the central importance of oral health to nutritional intake nor the impact of untreated PD on glycemic control and are silent on oral health provider representation on the integrated care teams proposed for comprehensive diabetic care delivery. Recent CPGs and position papers issued by cardiovascular societies $^{9,10}$ mainly defined therapeutic targets based on evidence from clinical trials, similarly remaining silent on evidence implicating a role for untreated periodontitis in sustaining dysglycemia ${ }^{6}$ and irrefutable statistics identifying cardiovascular diseases as the leading cause of mortality among diabetic patients. ${ }^{11}$

Historically, few medical CPGs have addressed dental considerations. The International Diabetes Federation 2009 guideline acceded that despite 'variable quality' surrounding evidence of links between oral-systemic disease, adverse impact of oral disease on quality of life, and cost effectiveness of prevention were compelling drivers for integrating oral care into diabetic management. ${ }^{12}$ The guideline promoted education of diabetic patients by providers on oral hygiene and awareness of xerostomia risk (dry mouth). Both the 2013 consensus report of the Joint European Federation for Periodontology and American Academy of Periodontology 
workshop on periodontitis and systemic diseases ${ }^{13}$ and metaanalysis of the impact of periodontal treatment on hemoglobin A1c levels (HbA1C), ${ }^{14}$ concluded that guideline provision surrounding periodontal care in diabetic patients was supportable and associated with efficacy, and was further supported by meta-analysis of level A clinical trial evidence demonstrating moderate reduction in $\mathrm{HbAlc}$ and inflammatory biomarker levels and improvement in oral indices post intervention. ${ }^{15}$ The American Academy of Oral Medicine also advanced evidence-based CPGs that include recommendations for optimizing clinical interventions to reduce risk of $\mathrm{PD}$, caries, and oral infection in patients with

Table 2. Sample healthcare models adopting integration of oral care into primary care or summaries of strategic approaches to integrated care for high risk patients.

\begin{tabular}{|c|c|c|c|}
\hline Objective & Population/Design & Outcomes to Date & Reference \\
\hline $\begin{array}{l}\text { Provide a practical framework } \\
\text { for integrating medical dental } \\
\text { care in diabetic management }\end{array}$ & Review & $\begin{array}{l}\text { Recommended: oral screening to } \\
\text { identify oral hallmarks of PD; } \\
\text { monitoring of modifiable risk factors } \\
\text { associated with T2DM } \\
\text { development; further evaluation of } \\
\text { POC screening; referral to medical } \\
\text { PCP; implementing inter- } \\
\text { professional education for medically } \\
\text { complex patient management; train } \\
\text { PCP to identify oral disease/ refer } \\
\text { for dental care. }\end{array}$ & Elangovan ${ }^{66}$ \\
\hline
\end{tabular}

\begin{tabular}{|c|c|}
\hline $\begin{array}{l}\text { Define role of the dental } \\
\text { professional in identifying } \\
\text { patients at risk for pre- } \\
\text { diabetes/diabetes }\end{array}$ & Review \\
\hline $\begin{array}{l}\text { Explore informatics } \\
\text { engagement to optimize } \\
\text { integrated care in various } \\
\text { healthcare settings supported } \\
\text { by interoperable trans- } \\
\text { European communication } \\
\text { platform(s) }\end{array}$ & $\begin{array}{l}\text { Health Service Platform } \\
\text { Architecture and End User } \\
\text { service development to support } \\
\text { T2DM management including: } \\
\text { vitals monitoring, glucose } \\
\text { sensing, feedback capacity, risk } \\
\text { assessment, event/alarm } \\
\text { management, insulin dosing } \\
\text { decision support, capturing } \\
\text { nutrition, pharmacological } \\
\text { treatment tracking with mobile } \\
\text { tablets platform compliant with } \\
\text { Medical Device Directives. }\end{array}$ \\
\hline
\end{tabular}

Operationalize an ICM encompassing specialty care, oral health, imaging, pharmacy and hospital care to in family health center-based primary care context

Characterize current practice patterns for integrating dental practitioners into the medical home model. Study focused on identifying best practices and education on strategic initiatives for medical-dental home set-up.

Reviewed risk factors and dental
provider role in identifying at-risk
patients, providing care education
and mediating triage to medical
care.
Study is in progress

\begin{tabular}{|c|c|c|}
\hline Family Health Center population & $\begin{array}{l}\text { Overview of accomplishing dental } \\
\text { integration through colocation of } \\
\text { services into primary care and } \\
\text { capacity building through training of } \\
\text { medical PCPs on dental issues }\end{array}$ & Olayiwola ${ }^{69}$ \\
\hline Environmental scan & $\begin{array}{l}\text { Four models were defined. State } \\
\text { was canvased to determine which } \\
\text { practice patterns were in place. } \\
\text { Challenges identified included } \\
\text { patient/provider education, impact } \\
\text { on staffing and staff, workflow and } \\
\text { integrating private practices. }\end{array}$ & $\begin{array}{l}\text { Oral Health } \\
\text { Commission }^{70}\end{array}$ \\
\hline
\end{tabular}

\begin{tabular}{|c|c|c|c|}
\hline Define an ICM algorithm & California residents & Algorithm defined. & $\begin{array}{l}\text { Diabetes } \\
\text { Coalition }^{71}\end{array}$ \\
\hline
\end{tabular}

PD, Periodontal disease; T2DM, Type 2 diabetes mellitus; POC, Point-of-care; PCP, Primary care provider; ICM, Integrated care model 


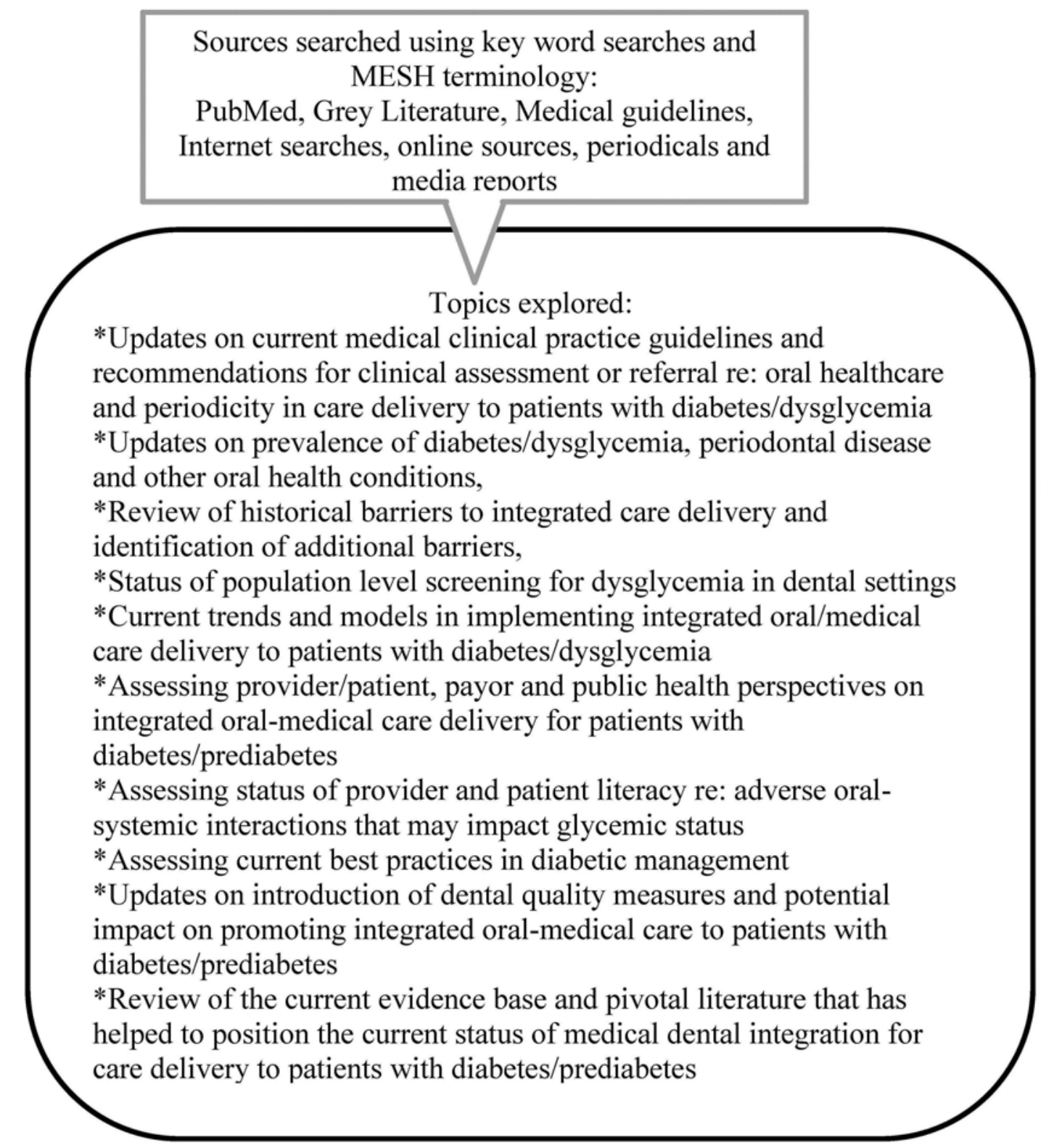

Figure 1. Overview of search strategy used to perform environmental scan.

xerostomia, diabetes, chronic obstructive pulmonary disease, and congestive heart failure. ${ }^{16}$ Gradually, just under half the states in the United States have incorporated some mention of oral care into CPGs for diabetic care (predominantly, recommendation for annual dental examination), citing C-level evidence and outcomes reported in initial trials performed with modest sample sizes demonstrating modest improvements in glycemic indices in response to nonsurgical periodontal intervention (Table 2).

Substantial barriers to integrated dental-medical healthcare delivery surrounding diabetes have been previously delineated and progress on resolution is summarized in Table 3 . Additional barriers identified in the course of this environmental scan and outlined subsequently herein include:
- Underestimation of true rates of periodontal disease when full mouth periodontal assessment was not applied;

- Lack of definition of best practices for PD risk assessment exacerbated by underlying diabetic pathophysiology or pharmacological diabetic management;

- Variability in tracking and reporting of dental care access and outcomes of surveillance approaches as challenges to achieving ICMs in disparity populations.

Surveillance Issues and Impact on Screening

Epidemiological characterization of periodontitis and diabetes over time has been associated with under-estimation of prevalence of both conditions and may impact on recommendations surrounding screening in the future. Since 1999, National Health and Nutrition Examination Survey data have been used to calculate PD prevalence in the absence of 
state/local surveillance data. Introduction of full-mouth periodontal examination, replacing previous partial-mouth periodontal assessment as the gold standard in 2009, identified systematic under-estimation of periodontitis prevalence by $50 \%-60 \%{ }^{17}$ Updated case definitions for population-based surveillance of periodontitis (2012) incorporated definition of a new mild periodontitis category expanding on existing definitions for moderate and severe disease, effectively increasing total prevalence estimates by $31 \% .{ }^{18}$ Subsequently, updated prevalence estimates of periodontitis $(2015)^{2}$ following full-mouth periodontal examination implementation and application of the updated case definitions are estimated at $46 \%$ in US adults ( 65 million people), with nearly $9 \%$ affected by severe periodontitis. Periodontitis prevalence was highest in Hispanic, non-Hispanic Black, and non-Hispanic Asian populations $(63.5 \%, 59 \%$, and $50 \%$, respectively) and positively associated with increasing age, male gender, and socio-economic indicators, with nearly a two-fold difference in prevalence based on economic tier or level of education.

Similarly, prevalence estimates of diabetes have varied, largely due to recent shifts in stringency of criteria used to classify diabetic and prediabetic status, effectively increasing by $75 \%$ the number of individuals newly categorized as diabetic across the spectrum of age between 1988 to $2010 .{ }^{19}$ Based on current definitions, one in three persons is projected to have diabetes by 2030 , while dynamic modelling predicted $25 \%$ to $28 \%$ prevalence by $2050 .{ }^{3}$ In light of data demonstrating association between periodontitis and chronic systemic conditions, ${ }^{20,21}$ these new prevalence estimates compellingly promote revisiting screening, intervention and effective interdisciplinary ICMs.

A 2015 report by the Wisconsin Department of Health Services underlines that the widely-quoted ' $70 \%$ ' frequency estimate for 'an annual dental visit' by the US population based on Behavioral Risk Factor Surveillance Survey ${ }^{22}$ data does not apply to disparity populations, reporting that approximately $50 \%$ of adults with incomes below $\$ 50,000$ were in need of dental care. ${ }^{23}$ The modest increase in access (from 34\% to 40\%) reported in Wisconsin in 2009 for lowincome populations noted mainly in counties located within the overlapping Marshfield Clinic/Family Health Center Service Area, was partially attributable to a strategicallyestablished, integrated medical-dental healthcare delivery system inclusive of regional dental infrastructure established to mitigate access barriers for low income and under- or uninsured populations. ${ }^{24}$

\section{Current Screening Trends}

Practice patterns for oral and medical healthcare delivery reflect sustained siloing of medical and dental healthcare delivery models and their respective independent reimbursement systems. Currently, four organizational juxtapositions have been modelled relative to implementation of Integrated Care Model (ICM)-based care delivery, including

Table 3. Identified barriers to achieving integrated oral-medical healthcare integration and delivery in management of patients with T2DM.

- $\quad$ Siloed medical and dental healthcare practice models and parallel payer reimbursement policies
- $\quad$ Lack of research on best practices for achieving integration and research defining outcomes
associated with models testing integration and implementation.
- $\quad$ Low/ no emphasis on oral health in most CPGs attributable on lack of
- $\quad$ Level A evidence demonstrating oral infection/inflammation as causal to diabetes exacerbation
- $\quad$ Low oral health literacy among diabetic patients, especially among disparity populations
of oral health data in most commercial EHRs
- $\quad$ Lack of research on best practices for cross-disciplinary screening, tools and cost is lacking,
-
- $\quad$ Lack of research defining impact on clinical workflow of oral health integration into diabetic
contributing to low provider acceptability
-
management
-
assessment is not applied.
- $\quad$ Lack of definition of best practices for PD risk assessment exacerbated by underlying diabetic
pathophysiology or pharmacological diabetic management
- $\quad$ Variability in tracking and reporting of dental care access and outcomes of surveillance approaches
as challenges to achieving ICMs in disparity populations

The table summarizes previously identified barriers to dental-medical integrated care model implementation. Additional barriers to achievement of ICMs presented in this report are shown in shaded fields.

T2DM, Type 2 diabetes mellitus; CPG, Clinical Practice Guidelines; EHR, Electronic health record; PD, Periodontal disease; ICM, Integrated care model 
feasibility of health screening. Relative success of screening and implementation of ICMs is largely defined by the proximity of the medical and dental practices and degree to which are they are integrated. Implementation of ICMs was predicted to be most highly effective in fully-integrated medical-dental systems with integrated health records and referral systems. Moderate integration was projected for co-located medical-dental practices or for those with a primary care provider service focus. Challenges to integration increased proportionally with decreased: (a) relational connections, (b) primary care provider focus and (c) proximity of the dental and medical settings. In the latter juxtaposition, projections included that highly disconnected providers reliant on a 'cooperation/ collaboration' as the operative model, were least likely to implement effective ICMs. ${ }^{25}$

Notably, screening for diabetes in primary care settings including dental settings and oral examination in the medical setting are not currently-recommended standards of care, despite increasing prevalence of both PD and T2DM. United States Preventive Service Task Force cited lack of a sufficient evidence base to support screening for diabetes in $2008,{ }^{26}$ and re-review by United Kingdom's parallel National Institute for Health Research in 2013 continued to support relegation of 'dental recall for oral health screening' for diabetics to the 'static list' for the next 5 years. ${ }^{27}$ Consequently, dental screening remains absent from current algorithms published by the Institute for Clinical Systems Improvement ${ }^{28}$ guiding diagnosis, management, and quality tracking parameters for adults with diabetes. Notably, a 2014 review concluded that, based on evidence-based support and demonstrated costeffectiveness, screening of high-risk dental patients was defensible. ${ }^{29}$

\section{Quality Assessment Status}

'Guideline Advantage', jointly-established by the ADA, American Heart Association, and American Cancer Association, proposes an interdisciplinary approach to develop effective, evidence-based guidelines and scientific statements in the context of meaningful use to achieve standardized quality measures for clinical care delivery within the scope of state-of-the-art technology in outpatient settings. ${ }^{30}$ However, guidelines for integrated point-of-care (POC) across the siloed primary care settings present barriers to their incorporation into standard practice. Whereas the 2015 Health Effectiveness Data Information Set measures issued by the National Committee for Quality Assurance ${ }^{31}$ included annual HbAlc and lipid panel assessment, and screening for nephropathy, retinopathy, and hypertension, quality measures tracking oral health remained absent despite:

(1) identification of periodontitis as an early complication ${ }^{32}$ and independent risk factor for diabetes; ${ }^{33}$

(2) evidence demonstrating bidirectional exacerbation between periodontitis and diabetes supported by systematic reviews; ${ }^{1}$
(3) evidence of modest reductions in HbAlc following PD treatment demonstrated in some studies; ${ }^{4,34-36}$

(4) documentation of higher oral pathogen prevalence in prediabetic patients without periodontitis. ${ }^{37}$

A recent study also proposed periodontitis as an independent risk factor contributing to hyperlipidemia. ${ }^{38}$ Increasingly, revisiting current paradigms for ICM-based delivery in medical- dental settings is critical, timely, and responsive to patient-centric care.

Newly-published accountable care organization quality performance standards released in January $2015^{31}$ surrounding diabetic care include only: 'HbAlc: poor control' and 'allcause unplanned admission.' Stated rationale for their inclusion is 'provision of coordinated patient-centered management, improved population health, and lower cost' and a vision wherein 'incentivized providers collaborate to optimize the best system of care by partnering appropriately.' Notwithstanding, standards for oral health integration remain largely absent.

\section{Future Directions in Screening}

Recent pilot studies have begun to explore prevalence of undiagnosed diabetes, prediabetes, and dyslipidemia in clinical dental settings (Table 4). Moreover, recent field trials of integrated care delivery models (ICM) implemented in various healthcare settings have been reported with some examples cited in Table 2. These studies have examined feasibility and reliability, quality assurance, ${ }^{39}$ acceptability, ${ }^{40}$ and challenges associated with POC screening. Deterrents to POC screening to date include cost; reimbursement structures; requirement for dental practices to address Clinical Laboratory Improvement Amendment (CLIA) certification; POC HbAlc sensitivity (estimated at $\sim 65 \%$ ); ${ }^{41}$ variability of glucometer accuracy; ${ }^{42}$ and operator competency training/tracking requirement $^{39}$ for POC screening. These collectively contribute potential for high false positive rates and low patient/provider acceptability.

Notably, a large number of algorithms to predict dysglycemia have been defined by modelling a range of candidate factors as surrogates for, or adjuncts to, biological determination of glycemic levels, with some models incorporating dental parameters as predictors of pre-/T2DM. Model performance varied widely on positive predictive power, and systematic assessment of utility and portability of existing models to other patient populations is pending. A systematic review of current risk prediction models for (pre)/diabetes flagged inappropriate approaches to statistical modelling in the development of some models as a concern, and subsequently limited systematic analyses to only those models developed through application of multivariate logistic regression modeling. ${ }^{43}$

Other potential screening methodologies are being explored. Review of fasting glucose measures available in health plan 
Table 4. Studies piloting estimation of prevalence of dysglycemia in dental settings.

\begin{tabular}{|c|c|c|c|}
\hline Screening Tools & Population/Sample Size & $\begin{array}{l}\text { Estimated Prevalence of } \\
\text { Dysglycemia }\end{array}$ & Reference \\
\hline $\begin{array}{l}\text { Risk modeling for diabetes/ } \\
\text { pre-diabetes; factors: missing } \\
\text { teeth, gender, hypertension } \\
\text { body mass index }>35 \mathrm{~kg} / \mathrm{m}^{2} \text {, } \\
\text { dyslipidemia. }\end{array}$ & $\begin{array}{l}\text { Dental patients } \pm \\
\text { periodontitis with no } \\
\text { diabetes diagnosis; fasting } \\
\text { plasma glucose }>110 \mathrm{mg} / \mathrm{dl} \\
\mathrm{N}=1033\end{array}$ & $\begin{array}{l}30 \% ; \\
\text { ( 20\% risk attributed to modeled } \\
\text { factors) }\end{array}$ & Herman $^{72}$ \\
\hline $\begin{array}{l}\text { Periodontal examination data } \\
\text { plus self-reported medical } \\
\text { history assessment }\end{array}$ & $N=4830$ & $\begin{array}{l}\text { Undiagnosed T2DM: } \\
\text { range: } 27-53 \%\end{array}$ & Borrell $^{73}$ \\
\hline $\begin{array}{l}\text { POC A1C test and self- } \\
\text { reported risk factor } \\
\text { assessment }\end{array}$ & $\mathrm{N}=104$ & Undiagnosed diabetes: $45 \%$ & Franck $^{74}$ \\
\hline $\begin{array}{l}\text { POC A1C test and American } \\
\text { Diabetic Association risk } \\
\text { survey }\end{array}$ & $\begin{array}{l}\geq 45 \text { years of age } \\
N=1022\end{array}$ & $\begin{array}{l}\text { Diabetes detection rate: } 40 \% \text { based } \\
\text { on A1C screen; (risk survey lacked } \\
\text { reliability) }\end{array}$ & Genco $^{75}$ \\
\hline $\begin{array}{l}\text { POC random plasma glucose } \\
\text { test and } \geq 1 \text { risk factor for } \\
\text { diabetes; or diagnosis of } \\
\text { diabetes or prediabetes }\end{array}$ & $\begin{array}{l}\text { Dental Practice-Based } \\
\text { Research Network (DPBRN) } \\
\text { patients } \\
\mathrm{N}=418\end{array}$ & $\begin{array}{l}31 \% \text { outside of normal range: } \\
\text { hypoglycemic: } \\
6.7 \% \text { hyperglycemic: } 24 \%\end{array}$ & Barasch $^{76}$ \\
\hline $\begin{array}{l}\text { POC A1C, periodontal } \\
\text { examination; self-reported risk } \\
\text { factors; number of missing } \\
\text { teeth }\end{array}$ & $\begin{array}{l}>30 \text { years }(\text { Hispanic) or } \\
>40 \text { year non-Hispanic white } \\
\text { dental patients } \\
\mathrm{N}=601\end{array}$ & $\begin{array}{l}31.8 \% \text { with prediabetic } \mathrm{HbA} 1 \mathrm{C} \text { levels } \\
4.2 \% \text { with potentially undiagnosed } \\
\text { T2DM }\end{array}$ & Lalla $^{77}$ \\
\hline $\begin{array}{l}\text { BMI, waist circumference, fat } \\
\% \text {, POC } \mathrm{HbA} 1 \mathrm{C} \text {, health } \\
\text { questionnaire, periodontal } \\
\text { examination and radiograph }\end{array}$ & $\begin{array}{l}\text { Danish dental patients } \\
\mathrm{N}=291\end{array}$ & $\begin{array}{l}27.1 \% \text { with prediabetic } \mathrm{HbA} 1 \mathrm{C} \text { levels } \\
3.1 \% \text { with potentially undiagnosed } \\
\text { T2DM }\end{array}$ & Holm $^{78}$ \\
\hline
\end{tabular}

POC, Point-of-care; PD, Periodontal disease; T2DM, Type 2 diabetes mellitus; A1C, Hemoglobin A1C; BMI, Body mass index

data effectively identified individuals with high dysglycemia risk. ${ }^{44}$ Non-invasive skin fluorescence spectroscopy has been developed with capacity to measure advanced glycation end products levels associated with diabetes in $\sim$ one minute. Initial trials demonstrated higher differential sensitivity compared to all current glycemic laboratory tests. ${ }^{41}$ Testing in multi-ethnic populations and larger trials and US Food and Drug Administration approval is pending. A new clinical trial (2014) is evaluating sensitivity of a new saliva-based metabolomic test developed by Weill Cornell Medical College (Qatar) as a screening tool for dyslipidemia based on demonstration of lower levels of anhydroglucitol in saliva of diabetics. ${ }^{45}$ The National Institute for Craniofacial Research and Delta Dental are pursuing saliva-based diabetic screening and improved classification of periodontitis based on evidence supporting multifactorial pathophysiological triggers manifesting a common presentation ${ }^{46}$ Identifying individuals at higher risk for dysglycemia and refractory forms of periodontitis is especially important and initial capacity of microbiome research to profile genetic signatures of pathogens to distinguish PD profiles has been suggested ${ }^{47}$ However, such approaches remain exploratory with demonstration of clinical applicability pending.
Current Status of Integrating Oral Health into Primary Care Practice

Educational initiatives targeting providers are serving to advance cross-disciplinary awareness to set the stage for integration. The Academy of Dental Learning and Occupational Safety and Health Administration Training issued a continuing education program targeting training of dentists surrounding the dental patient with diabetes recently updated in $2015 .{ }^{48}$ Several recent surveys of medical and dental professionals demonstrated favorable attitudes toward medical-dental care integration for patients with complex disease. Studies evaluating attitudes of PCPs towards medical screening by dental practitioners reported high receptivity and attribution of value. ${ }^{40}$ Reports examining practice behaviors and knowledgeability of dentists and perceived barriers to medical assessment of patients reported: (1) high knowledgeability of dentists regarding relational aspects of oral-systemic disease; (2) willingness to engage risk factor screening, patient education, and collaborative interaction with medical providers; and (3) improved capture rates of glycemic and blood pressure measures in medical histories, 
Table 5. Sample of recent studies demonstrating impact of lifestyle intervention or PD intervention in patients with prediabetes/T2DM on oral and/or glycemic indices.

\begin{tabular}{|c|c|c|c|}
\hline Study Description & Population & Outcomes & Reference \\
\hline $\begin{array}{l}\text { Education/counseling applying } \\
\text { motivational approaches to achieve } \\
\text { lifestyle intervention coupled with } \\
\text { instruction on oral hygiene; follow up at } \\
3 \& 6 \text { months was conducted. Patients } \\
\text { receiving standard care served as } \\
\text { controls. }\end{array}$ & $\begin{array}{l}\text { Elderly diabetic patients } \\
\text { (Thailand) }\end{array}$ & $\begin{array}{l}\text { Statistically significant } \\
\text { reduction in A1C and FPG } \\
\text { levels and improved oral } \\
\text { indices in interventional } \\
\text { group compared to standard } \\
\text { care }\end{array}$ & Saengtipbovorn ${ }^{79}$ \\
\hline $\begin{array}{l}\text { Lifestyle intervention in primary } \\
\text { healthcare setting with } 2.3 \text { year follow- } \\
\text { up }\end{array}$ & $\begin{array}{l}\text { Prediabetic patients } \\
\text { aged } \\
30-60 \text { years vs usual } \\
\text { care in patients with } \\
\text { A1C }<5.7 \text { (Japan) }\end{array}$ & $\begin{array}{l}\text { Incidence of T2DM in } \\
\text { patients receiving } \\
\text { intervention was lower in } \\
\text { interventional group than in } \\
\text { the usual care group }\end{array}$ & Sakane $^{80}$ \\
\hline $\begin{array}{l}\text { Examined randomized controlled trials } \\
\text { testing efficacy of lifestyle interventions } \\
\text { in patients presenting with impaired } \\
\text { glucose tolerance }\end{array}$ & $\begin{array}{l}\text { Meta-analysis of } \\
\text { randomized controlled } \\
\text { trials }\end{array}$ & $\begin{array}{l}7 \text { trials including }>5600 \\
\text { patients demonstrated } \\
\text { reduced T2DM in patient with } \\
\text { IGT }\end{array}$ & Yoon $^{81}$ \\
\hline $\begin{array}{l}\text { Examined glycemic and metabolic } \\
\text { outcomes in randomized controlled } \\
\text { trials examining impact of periodontal } \\
\text { treatment in diabetic patients }\end{array}$ & $\begin{array}{l}\text { Meta-analysis of } \\
\text { randomized controlled } \\
\text { trials }\end{array}$ & $\begin{array}{l}5 \text { trials including } 315 \text { patients } \\
\text { showed statistically } \\
\text { significant reduction in } \\
\text { glycemic indices but not lipid } \\
\text { variables }\end{array}$ & Sgolastra ${ }^{82}$ \\
\hline
\end{tabular}

PD, Periodontal disease; T2DM, Type 2 diabetes mellitus; A1C, Hemoglobin A1C; FPG, Fasting plasma glucose; IGT, Impaired glucose tolerance

especially among younger practitioners. Provider perception of low patient acceptance attributable to concerns surrounding additional cost and healthcare access, especially in rural settings, was identified. ${ }^{49,50} \mathrm{~A} 2015$ consensus paper providing a framework and recommendations for advancing interprofessional education, multidisciplinary teamwork, and improvement in health literacy surrounding periodontitis is noteworthy. ${ }^{51}$

Direct dental treatment costs account for $4.6 \%$ of global expenditure $\left(>120\right.$ billion in North America alone), ${ }^{52}$ compelling dental-medical practice reintegration in some countries and US states, in response to medical practice redesign accelerated by the 2015 accountable care initiative. Accountable care focus in the context of diabetes has increased quality care and cost reductions through proactive practice re-design.

To date, the most effective clinical management of dysglycemic patients currently defined are aligned with ICMs (examples summarized in Table 5). Successful models implementing dental interventions (examples in Table 1 and 4) may be similarly responsive but require portability assessment. Incorporation of additional patient-centric performance measures to balance current metrics has been promoted $^{53}$ and quality measure implementation is essential to tracking efficacy of ICM implementation.
Improvement in clinical outcomes was demonstrated by a meta-regression analysis of $>100$ randomized controlled/ uncontrolled trials among diabetic populations in studies incorporating chronic care model components. ${ }^{54}$ Chronic care model components center on integration of adequate resources, evidence-based policies, and operational delivery design of the healthcare institution (to include committed, appropriate primary care provision, patient diabetes selfsupport education, and availability of electronic health records for data capture and quality tracking). Evidencebased review supported adoption of chronic care components as the ideal infrastructure for achieving successful clinical practice redesign. ${ }^{55}$ Specifically, the following elements were distilled as the most effective contributors to diabetic management: professional education/intervention, establishment of provider champions, self-support and selfmanagement patient education facilitated by nurse practitioners, adherence to CPGs, implementing process measures, and performance feedback. ${ }^{55}$ These parameters underline the critical need for inclusion of dental providers as primary care providers and increased visibility of oral health in CPGs.

\section{Public Health Perspectives}

Access to dental care for low income and disparity populations persists as an issue with major impact on quality of life. Dental service cost in the United States in 2014 was \$113.5 billion, with an estimated $40 \%$ constituting out-of-pocket 
$\operatorname{cost},^{56}$ disproportionately impacting disparity populations. To address persistence of access disparity, just under half of US states have dental coverage allowances for high-risk Medicaid patients with high prevalence of periodontitis and complex diseases including diabetes. Integration of public health with dentistry and medicine was recently advanced as the healthcare service delivery model for underserved populations, but efficacy research in this area is sparse. ${ }^{57}$ Due to successful interventional models created by Family Health Centers, Centers for Medicare/Medicaid Service continues to partner with Family Health Centers to solve access disparities and reduce cost of care to underserved populations. Guidelines for incorporating improved dental benefits have recently been released to assist the insurance marketplace. ${ }^{58,59}$ While recent studies report cost savings in association with oral health maintenance as a strategic approach to establishing/ facilitating glycemic control in diabetic patients, ${ }^{60}$ methodological approaches to analyses have been challenged, ${ }^{61}$ and further well-designed studies are needed to validate predictions.

\section{Conclusion and Future Directions}

A role for dental providers in risk factor management to delay/prevent diabetes onset/progression has been advanced. ${ }^{62}$ Notably, odds for periodontitis increases proportionally with every unit increase in $\mathrm{HbAlc},{ }^{63}$ and periodontal treatment was projected to reduce $\mathrm{HbA1c}$ with efficacy equivalent to supplementary pharmacological intervention. ${ }^{35}$ Updates on 'dental recall' clinical guidelines updated in 2011 by the National Institute for Health and Clinical Excellence (scheduled review: 2014) remain pending and periodicity, particularly during treatment, remains to be defined especially for the diabetic population. ${ }^{64}$ Quality tracking implementation in the dental setting would support analyses of dental health outcomes relative to frequency of dental visits in dental patients relative to their oral health status. To date, lifestyle intervention including pharmacological management (Table 5) and bariatric surgery in morbidly obese patients have demonstrated greatest efficacy in delaying/preventing diabetes onset in pre-diabetic individuals, achievement of glycemic control and improvement in oral indices. ${ }^{65}$ In the absence of screening, maintenance of oral health, healthy lifestyles promotion, emphasis on increasing health literacy and emphasis on implementing integrated medical-dental care delivery provide current best practices for mitigating disease onset or progression. Emerging non-invasive technologies surrounding glycemic assessment may mitigate screening barriers in the dental setting and may be incorporated as components of effective ICMs. Resolution of key persistent pivotal barriers to translation of ICMs into clinical care will benefit from more 'A'-level evidence. For example, well designed studies are needed to assess cost effectiveness of addressing periodontitis as a modifiable risk factor in the context of maintaining glycemic control in order to define downstream capacity to leverage health benefits associated with reduction in the levels of oral and systemic inflammatory processes.

\section{References}

1. Casanova L, Hughes FJ, Preshaw PM. Diabetes and periodontal disease: a two-way relationship. British Dental J 2014;217:433-437.

2. Eke PI, Dye BA, Wei L, Slade GD, Thorton-Evans GO, Borgnakke WS, Taylor GW, Page RC, Beck JD, Genco RJ. Update on prevalence of periodontitis in adults in the United States: NHANES 2009-2012. J Periodontol 2015;86:611622.

3. Boyle JP, Thompson TJ, Gregg EW, Barker LE, Willianson DF. Projection of the year 2050 burden of diabetes in the US adult population: dynamic modeling of incidence, mortality and prediabetes prevalence. Popul Health Metri 2010 8:29.

4. American Diabetes Association. Standards of medical care in diabetes-2015 abridged for primary care providers. Clin Diabetes 2015;33:97-111.

5. American Diabetes Association. Standards of Medical Care in Diabetes 2016. Diabetes Care 2016;39:Suppl 1:S1-S112. Available at: http://care.diabetesjournals.org/content/ suppl/2015/12/21/39.Supplement_1.DC2/2016-Standards-ofCare.pdf. Accessed August 26, 2016.

6. Borgnakke WS, Ylostalo PV, Taylor GW, Genco RJ. Effect of periodontal disease on diabetes, systematic review of epidemiologic observational evidence. J Periodontol 2013;84:S135-152.

7. National Diabetes Education Initiative. Treatment guidelines repository. Available at: http://www.ndei.org/ treatmentguidelines.aspx.html. Accessed August 28, 2016.

8. Handelsman Y, Bloomgaden ZT, Grunberger G, Umpierrez G, Zimmrman RS, Bailey TS, Blonde L, Bray GA, Cohen AJ, Dagogo-Jack S, Davidson JA, Einhorn D, Ganda OP, Garber AJ, Garvey WT, Henry RR, Hirsch IB, Horton ES, Hurley DL, Jellinger PS, Jovanovič L, Lebovitz HE, LeRoith D, Levy P, McGill JB, Mechanick JI, Mestman JH, Moghissi ES, Orzeck EA, Pessah-Pollack R, Rosenblit PD, Vinik AI, Wyne K, Zangeneh F. American Association Clinical Endocrinologists and American College of Endocrinology clinical practice guidelines for developing a diabetes mellitus comprehensive care plan - 2015. Endocr Pract 2015;21 Suppl 1:1-87.

9. Fox CS, Golden SH, Anderson C Bray GA, Burke LE, de Boer IH, et al. Deedwania P, Eckel RH, Ershow AG, Fradkin J, Inzucchi SE, Kosiborod M, Nelson RG, Patel MJ, Pignone M, Quinn L, Schauer PR, Selvin E, Vafiadis DK; American Heart Association Diabetes Committee of the Council on Lifestyle and Cardiometabolic Health, Council on Clinical Cardiology, Council on Cardiovascular and Stroke Nursing, Council on Cardiovascular Surgery and Anesthesia, Council on Quality of Care and Outcomes Research, and the American Diabetes Association. Update on Prevention Of Cardiovascular Disease In Adults With Type 2 Diabetes In Light Of Recent Evidence: A Scientific Statement from the American Heart Association and the American Diabetes Association. Circulation 2015;132:691-718.

10. Task Force on diabetes, pre-diabetes, and cardiovascular diseases of the European Society of Cardiology (ESC); European Association for the Study of Diabetes (EASD), Ryden, L, Grant PJ, Anker SD, Berne C, Danchin N, Deaton C, Deaton C, Escaned J, Hammes HP, Huikuri H, Marre M, Marx N, Mellbin L, Ostergren J, Patrono C, Seferovic P, Uva MS, Taskinen MR, Tendera M, Tuomilehto J, Valensi P, Zamorano JL. ESC guidelines on diabetes, prediabetes, and cardiovascular diseases developed in collaboration with the EASD-summary. Diab Vasc Dis Res 2014;11:133-173.

11. Matheus AS, Tannus LR, Cobas RA, Palma CC, Negrato CA, Gomes MB. Impact of diabetes on cardiovascular disease: an update. Int J Hypertens 2013;2013:653-789. 
12. International Diabetes Federation. Clinical Guidelines Task Force. IDF Guideline on oral health for people with diabetes. Brussels: International Diabetes Federation, 2009. Available at: http://www.idf.org/guidelines/diabetes-and-oral-health/ guideline. Accessed December 11, 2015.

13. Chapple IL, Genco R; working group 2 of the joint EFP/AAP workshop. Diabetes and periodontal diseases: consensus report of the Joint EFP/AAP Workshop on Periodontitis and Systemic Diseases. J Periodontol 2013;84:S106-S112.

14. Wang X, Han X, Guo X, Luo G, Wang D. The effect of periodontal treatment on hemoglobin a1c levels of diabetic patients: a systematic review and meta-analysis. PLoS One 2014;9:e108412.

15. Sgolastra F, Severino M, Pietripaoli D, Gatto R, Monaco A. Effectiveness of periodontal treatment to improve metabolic control in patients with chronic periodontitis and type 2 diabetes: a meta-analysis of randomized controlled trials. J Periodontol 2013:84:958-973.

16. Rhodus NL, Miller CS. Clinicians guide to treatment of medically complex dental patients. 4th ed. Edmonds, Washington: American Academy of Oral Medicine; 2009.

17. Eke PI, Thorton-Evans GO, Wei L, Bornakke WS, Dye BA. Accuracy of NHANES periodontal examination protocols. J Dent Res 2010;89:1208-1213.

18. Eke PI, Page RC, Wei L, Thorton-Evans G, Genco RJ. Update of the case definitions for population-based surveillance of periodontitis. J Periodontol 2012;83:1449-1454.

19. Cheng YJ, Imperatore G, Geiss LS, Wang J, Saydah SH, Cowie CC, Gregg EW. Secular changes in the age-specific prevalence of diabetes among U.S. adults: 1988-2010. Diabetes Care 2013;36:2690-2696.

20. Lockhart PB, Bolger AF, Papapanou PN, Osinbowale O, Trevisan M, Levison ME, Taubert KA, Newburger JW, Gornik HL, Gewitz MH, Wilson WR, Smith SC Jr, Baddour LM; American Heart Association Rheumatic Fever, Endocarditis, and Kawasaki Disease Committee of the Council on Cardiovascular Disease in the Young, Council on Epidemiology and Prevention, Council on Peripheral Vascular Disease, and Council on Clinical Cardiology. Periodontal disease and atherosclerotic vascular disease: does the evidence support an independent association?: a scientific statement from the American Heart Association. Circulation 2012;1125:2520-2544.

21. Cullinan MP, Seymour GJ. Periodontal disease and systemic illness: will the evidence ever be enough? Periodontol 2000 2013;62:271-286.

22. U.S. Department of Health and Human Service. Centers for Disease Control. Vital and Health Statistics. Summary Health Statistics for U.S. Adults: National Health Interview Survey, 2012. February 2014. Available at: http://www.cdc.gov/nchs/ data/series/sr_10/sr10_260.pdf. Accessed 7 Dec 2015.

23. Wisconsin Department of Health Services. 2015-The oral health of Wisconsin Adults. Available at: https://www.dhs.wisconsin. gov/publications/p01074.pdf. Accessed August 30, 2016.

24. Qualis Health. Oral Health: an essential component of primary care. White Paper. June 2015. Available at: http://www. safetynetmedicalhome.org/sites/default/files/White-PaperOral-Health-Primary-Care.pdf. Accessed December 15, 2015.

25. Grantsmakers in Health Returning the mouth to the body: integrating oral health and primary care. Issue Brief \#40, September 2012 Washington DC. Available at: http://www. gih.org/files/FileDownloads/Returning_the_Mouth_to_the Body_no40_September_2012.pdf. Accessed August 29, 2016.

26. Norris SL, Kansagara D, Bougatsos C, Fu R; U.S. Preventive Services Task Force. Screening adults for type 2 diabetes: a review of the evidence for the U.S. Preventive Services Task Force. Ann Intern Med 2008;148:855-868.
27. Waugh NR, Shyangdan S, Taylro-Phillips, S Suri G, Hall B. Screening for type 2 diabetes: a short report for the National Screening Committee. Health Technol Assess 2013;17:1-90.

28. Gavi S, Hensley J. Diagnosis and management of type 2 diabetes in adults: a review of the ICSI guideline. Geriatrics 2009;64:12-17,29.

29. Sultan A, Warreth A, Fleming P, MacCarthy D. Does the dentist have a role in identifying patients with undiagnosed diabetes mellitus? J Irish Dent Assoc 2014;60:298-303

30. Bufalino V, Bauman MA, Shubrook JH, Balch AJ, Boone C, Vennum K, Bradley S, Wender RC, Minners R, Arnett D; American Cancer Society; American Diabetes Association; American Heart Association. Evolution of "the guideline advantage"; lessons learned from the front lines of outpatient performance measurement. Diabetes Care 2014;37:17451750.

31. Center for Medicare and Medicaid Services. Accountable Care Organization 2015. Program analysis and quality performance standards narrative measure specification. Available at: https://www.cms.gov/medicare/medicare-fee-for-servicepayment/sharedsavingsprogram/downloads/ry2015-narrativespecifications.pdf. Accessed December 29, 2015.

32. Loe H. Periodontal disease. The sixth complication of diabetes mellitus. Diabetes Care 1993;16:329-334.

33. Demmer RT, Jacobs DR Jr, Desvarieux M. Periodontal disease and incident type 2 diabetes: results from the first National Health and Nutrition Examination Survey and its epidemiologic follow-up study. Diabetes Care 2008;31:13731379.

34. Wang TF, Jen IA, Chou C, Lei YP. Effects of periodontal therapy on metabolic control in patients with Type 2 diabetes mellitus and periodontal disease: a metaanalysis. Medicine (Baltimore) 2014;93:e292.

35. Engebretson S, Kocher T. Evidence that periodontal treatment improves diabetes outcomes: a systematic review and metaanalysis. J Periodontol 2013;84:S153-S169.

36. Merchant AT, Georgantopoulos P, Howe CJ, Virani SS, Morales DA, Haddock KS. Effect of long-term periodontal care on Hemoglobin A1C in Type 2 Diabetes. J Dental Res 2016;95:408-415.

37. Demmer RT, Jacobs Jr. DR, Singh A, Zuk, M, Rosenbaum M, Papapanou PN. Periodontal bacteria and prediabetes prevalence in ORIGINS: the Oral Infections, Glucose Intolerance and Insulin Resistance Study. J Dent Res 2015;94:201S-211S.

38. Kalsi DS, Chopra J, Sood A. Association of lipid profile test values, type 2 diabetes mellitus, and periodontitis. Indian J Dent 2015;6:81-84.

39. Dyhdalo KS, Howanitz PJ, Wilkinson DS, Souers RJ, Jones BA. Documentation of quality control and operator training at point-of-care testing: a College of American Pathologists Q-Probes study of 106 institutions. Arch Pathol Lab Med 2014;138:1444-1448.

40. Greenberg BL, Thomas PA Glick M, Kantor ML. Physician's attitudes toward medical screening in a dental setting. J Public Health Dent 2015;75:225-233.

41. Olson BP, Matter NI, Ediger MN, Hull EL, Maynard JD. Noninvasive skin fluorescence spectroscopy is comparable to hemoglobin A1c and fasting plasma glucose for detection of abnormal glucose tolerance. J Diabetes Sci Technol 2013;7:990-1000.

42. Hellman R. Glycemic variability in the use of POC glucose meters. Diabetes Spectrum 2012;25:135-140.

43. Collins GS, Mallett S, Omar O, Yu LM. Developing risk prediction models for type 2 diabetes: a systematic review of methodology and reporting. BMC Medicine 2011;9:103. 
44. McEwen LN, Adams SR, Schmittdiel JA, Ferrara A, Selby JV, Herman WH. Screening for impaired fasting glucose and diabetes using available health plan data. J Diabetes Complications 2013;27:580-587.

45. Suhre K. New test could revolutionize diabetes screening. Thomson Reuters ZAWYA. 201422 January. Available at: http://www.zawya.com/story/ZAWYA20140122102849/. Accessed December 29, 2015.

46. Valachovic RW Harnessing the potential of saliva. Charting Progress: ADEA, The Voice of Dental Education. July 2015. Available at: https://adeachartingprogress.wordpress. com/2015/07/15/harnessing-the-potential-of-saliva/. Accessed December 29, 2015.

47. Wang GP. Defining functional signature of dysbiosis in periodontal progression. Genome Med 2015;7:40.

48. Slim LH, Stegeman CA, Dentalcare.com. Diabetes: a multifaceted syndrome treatment-considerations in dentistry. Available at: http://www.dentalcare.com/en-US/dentaleducation/continuing-education/ce93/ce93.aspx?ModuleNam $\mathrm{e}=$ introduction \& PartID $=-1 \&$ SectionID $=-1$. Accessed August 30, 2016.

49. Wilder, RS, Bell KP, Phillips C, Paquette DW, Offenbacher S. Dentists' practice behaviors and perceived barriers regarding oral-systemic evidence: implications for education. J Dent Educ 2014;78:1252-1262.

50. Shimpi N, Schroeder D, Kilsdonk J, Chyou PH, Glurich I, Acharya A. Assessment of dental providers' knowledge, behaviour, and attitudes towards incorporating chairside screening for medical conditions: a pilot study. Journal of Dentistry and Oral Care Medicine 2015;2:102 109.

51. Kumarswamy A, Jin L, Iacono V, Byakod G, Chiu G, Duygu I, Fernandes B, Kemal Y, Loomer P, Masud M, Narongsak L, Pillai N, Shorab M, Tan B, Thakur R, Xuan DY, Zhang JC. Group E. Consensus paper. Interprofessional education and multidisciplinary teamwork for prevention and effective management of periodontal disease. J Int Acad Periodontol 2015; 17:84-86.

52. Listl S, Galloway J, Mossey PA, Marcenes W. Global economic impact of dental disease. J Dent Res 2015;94:1355-1361.

53. Saver BG, Martin SA, Adler RN, Candib LM, Deligiannidis KE, Golding J, Mullin DJ, Roberts M, Topolski S. Care that Matters: quality measurement and health care. PLoS Med 2015; 12:e1001902.

54. Stellefson M, Dipnarine K, Stopka C. The chronic care model and diabetes management in US primary care settings: a systematic review. Prev Chronic Dis 2013;10:E26.

55. Frolich A. Identifying organisational principles and management practices important to the quality of health care services for chronic conditions. Dan Med J 2012;59:B4387.

56. Centers for Medicare and Medicaid Services. National Health Expenditures 2014 highlights. Available at: https://www.cms. gov/Research-Statistics-Data-and-Systems/Statistics-Trendsand-Reports/NationalHealthExpendData/downloads/ highlights.pdf. Accessed December 29, 2015.

57. Northridge ME, Chenchen Y, Chakraborty B, Greenblatt AP, Mark J, Golembeski C, Cheng B, Kunzel C, Metcalf SS, Marshall SE, Lamster IB. A community-based oral public health approach to promote health equity. Am J Public Health 2015;105:S459-S465.

58. National Academy for State Health Policy. Snyder A, Kanchinadam K, Hess C, Dolan R. Improving integration of dental health benefits in health insurance marketplaces. April 2014. Available at: http://www.nashp.org/sites/default/files/ improving.integration.of_dental.health.benefits.in_.health. insurance.marketplaces_0.pdf. Accessed December 29, 2015.

59. Collins S, Piper KB, Owens G. The opportunity for health plans to improve quality and reduce costs by embracing primary care medical homes. Am Health Drug Benefits 2013;6:30-38.
60. Jeffcoat MK, Jeffcoat RL, Gladowski PA, Bramson JB, Blum JJ. Impact of periodontal therapy on general health:evidence form insurance data for five systemic conditions. Am J Prev Med 2014:47:166-174.

61. Sheiham A. Claims that periodontal treatment reduces costs of treating five systemic conditions are questionable. J Evid Based Dent Pract 2015;15:35-36.

62. Genco RJ, Genco FD. Common risk factors in the management of periodontal and associated systemic diseases: the dental setting and interprofessional collaboration. J Evid Based Dent Pract 2014;14 Suppl:4-16.

63. Garcia D, Tarima S, Okunseru C. Periodontitis and glycemic control in diabetes: NHANES 2009 to 2012. J Periodontol 2015;86:499-506.

64. National Institute for Health and Clinical Excellence. NICE guidelines on dental recall. London, UK. (2011 24 March). Available at: https://www.gov.uk/government/publications/ national-institute-for-health-and-clinical-excellence-niceguidelines-on-dental-recall. Accessed December 29, 2015.

65. Chen L, Pei JH, Kuang J, Chen HM, Chen Z, Li ZW, Yang HZ. Effect of lifestyle intervention in patients with type 2 diabetes: a meta-analysis. Metabolism 2015 64:338-347.

66. Elangovan S, Hertzman-Miller R, Karimbux N, Giddon D. A framework for physician dental collaboration in diabetes and periodontitis. Clin Diabetes 2014;32:188-192.

67. Lalla E, Lamster IB. Assessment and management of patients with diabetes mellitus in the dental office. Dent Clin N Am 2012;56:819-829.

68. Spanakis EG, Chiarugi F, Louroubali A, Spat S, Beck P, Asanin S, Rosengren P, Gergely T, Thestrup J. Diabetes management using modern information and communication technologies and new care models. Interact J Med Res 2012;1:e8.

69. Olayiwola JN, Bodenheimer T, Dube K, Willard-Grace R, Grumbach K. UCSF Center for Excellence in Primary Care. Facilitation care integration in Community Health Centers. Available at: http://www.blueshieldcafoundation.org/sites/ default/files/publications/downloadable/Executive_Summary_ Facilitating_Care_Integration_Mar_2014.pdf. Accessed December $\overline{12}, 20 \overline{1} 5$.

70. Oral Health Commission Safety Net Workgroup. Patient centered medical-dental home initiatives: a survey of current and future strategies to coordinate care in Rhode Island Sept 2011. Available at: http://www.oralhealth.ri.gov/documents/ PatientCenteredMedicalDentalHomeSurveyReportOHCSafetyNetWorkgroupReport2011.pdf. Accessed December 8, 2015.

71. Diabetes Coalition of California/Alameda Alliance for Health. Oral health care for people with diabetes. 2015. Available at: https://www.alamedaalliance.org/live-healthy/health-issues/ diabetes. Accessed December 8, 2015.

72. Herman WH, Taylor GW, Jacobson JJ, Burke R, Brown MB. Screening for prediabetes and type 2 diabetes in dental offices. J Public Health Dent 2015;75:175-182.

73. Borrell LN, Kunzel C, Lamster I, Lalla E. Diabetes in the dental office: using NHANES III to estimate probability of unknown disease. J Periodontal Res 2007:42:559-565.

74. Franck SD, Stollberg Bilich LA, Payne LE. Point of care HbA1c screening predicts diabetic status of dental patients. J Dent Hyg 2014;88:42-52.

75. Genco RJ, Schifferle RE, Dunford RG, Falkner KL, Hsu WC,Balukjian J. Screening for diabetes mellitus in dental practices: a field trial. J Am Dent Assoc 2014;145:57-64.

76. Barasch A, Safford MM, Qvist V, Palmore R, Gesko D, Gilbert GH. Dental Practice-Based Research Network Collaborative Group. Random blood glucose testing in dental practice: a community based feasibility study from the Dental PracticeBased Research Network. J Am Dent Assoc 2012;143:262269. 
77. Lalla E, Kunzel C, Burkett S, Cheng B, Lamster IB. Identification of unrecognized diabetes and prediabetes in a dental setting. J Dent Res; 2011;90:855-860.

78. Holm NC, Belstrom D, Ostergaard JA, Schou S, Holmstrup P, Grauballe MD. Identification of individuals with undiagnosed diabetes in a Danish cohort attending dental treatment. J Periodontol 2016;87:395-402

79. Saengtipbovorn S, Taneepanichskul S. Effectiveness of lifestyle change plus dental care program in improving glycemic and periodontal status in aging patients with diabetes: a cluster randomized controlled trial. J Periodontol 2015;86:507-515.

80. Sakane N, Sato J, Tsushita K, Tsujii S, Kotani K, Tominaqa M, Kawazu S, Sato Y, Usui T, Kamae I, Yoshida T, Kiyohara Y, Sato S, Tsuzaki K, Takahashi K, Kuzuya H; Japanese Diabetes Preventions Program (JDPP) Research Group. Effect of baseline HbA1c level on the development of diabetes by lifestyle intervention in primary healthcare settings: insight from subanalysis of Japan Diabetes Prevention Program. BMJ Open Diabetes Res Care 2014;2:e000003.

81. Yoon U, Kwok LL, Magkidis A. Efficacy of lifestyle interventions in reducing diabetes incidence in patients with impaired glucose tolerance: a systematic review of randomized controlled trials. Metabolism 2013;62:303-314.

82. Sgolastra F, Severino M, Pietropaoli D, Gatto R, Monaco A. Effectiveness of periodontal treatment to improve metabolic control in patients with chronic periodontitis with type 2 diabetes: a meta-analysis of randomized clinical trials. J Periodontol 2013;84:958-973.

\section{Author Affiliations}

Ingrid Glurich, PhD*; Gregory Nycz广; and Amit Acharya, $B D S, P h D^{*}$

*Center for Oral and Systemic Health, Marshfield Clinic

Research Institute, Marshfield, Wisconsin, USA

$\dagger$ Family Health Center of Marshfield, Marshfield Clinic,

Marshfield, Wisconsin, USA 